$3-1-2003$

\title{
Benefits of a comprehensive undergraduate teaching assistant program
}

Christopher D. Goff

University of the Pacific, cgoff@pacific.edu

Brigitte Lahme

Sonoma State University

Follow this and additional works at: https://scholarlycommons.pacific.edu/cop-facarticles

Part of the Curriculum and Instruction Commons, Higher Education Commons, Mathematics Commons, and the Science and Mathematics Education Commons

\section{Recommended Citation}

Goff, C. D., \& Lahme, B. (2003). Benefits of a comprehensive undergraduate teaching assistant program. PRIMUS: Problems, Resources, and Issues in Mathematics Undergraduate Studies, 13(1), 75-84. DOI: 10.1080/10511970308984047

https://scholarlycommons.pacific.edu/cop-facarticles/266 


\title{
Benefits of a Comprehensive Undergraduate Teaching Assistant Program
}

\author{
Abstract \\ The Undergraduate Teaching Assistant (UTA) Program at the University of Arizona \\ exposes students to many different aspects of teaching an undergraduate mathematics \\ course. The program's breadth generates various qualitative and quantitative benefits. \\ Some of these benefits are that the UTAs improve their mathematics and communications \\ skills, instructors have additional support both inside and outside the classroom, and \\ mathematics students in classes with UTAs enjoy their mathematics classes more than \\ students in similar classes without UTAs.
}

Key Words: Undergraduate teaching assistants, qualitative and quantitative benefits

\section{Introduction}

The University of Arizona Mathematics Department has long used undergraduates as graders and tutors for lower division classes, as is the practice at many schools around the country. In the spring semester of 2000 , the mathematics department initiated a new Undergraduate Teaching Assistantship Program that allows students to gain experience beyond just grading and tutoring. In the new program, each undergraduate teaching assistant (UTA) is paired with an instructor teaching a lower division mathematics class of approximately 35 students. After receiving initial training, the UTAs become actively involved in several different aspects of mathematics instruction, such as facilitating inclass group work, holding study sessions and office hours, and grading homework. Moreover, each UTA works in the department's drop-in tutoring room and attends regular training sessions throughout the semester. Funding for the program comes 
through matching funds for the department's VIGRE grant (Vertical Integration of Graduate Research and Education) through the National Science Foundation.

In this article, we describe the program and its positive impact on undergraduate mathematical instruction. In particular:

1. The UTAs benefited by improving their communication skills, deepening their mathematical content knowledge and understanding, and gaining insight into what is involved in teaching mathematics.

2. Instructors in the mathematics department benefited by having more options in their teaching style and being able to offer additional help to their students. The department itself benefited from having competent tutors interested in quality instruction.

3. The students benefited by having more support both in and out of class.

\section{Other Programs}

Mathematics departments in many universities use undergraduate students as teaching assistants. In most cases, advanced mathematics students are employed as graders or tutors for lower division classes such as college algebra and calculus. Most large universities, such as the University of Minnesota, Georgia Tech, Michigan State University, Oklahoma State University, and the University of Texas, employ undergraduates as graders and tutors. Smaller schools like South Dakota School of Mines and Technology and the University of the Pacific also utilize undergraduates in these capacities. The selection process and training of UTAs varies from school to school. At 
most schools, training does not exist or is minimal. The "Teaching Mathematics" course at McMaster University, and others like it, are exceptions. At McMaster, UTAs are required to sign up for a class that accompanies them through the semester and discusses topics such as teaching styles and reformed vs. traditional calculus.

Very little research has been conducted to study the impact undergraduate teaching assistants have on the quality of undergraduate education in a department, mathematics or otherwise. Studies concerning undergraduate teaching assistants have mostly been conducted in fields like Communications and Psychology, where UTAs are utilized in large classes to facilitate group discussions $[1,4,6]$, or in Physics or Computer Science where UTAs are employed to help in labs $[2,3]$. Some of the studies that have been done in these fields have focused primarily on the benefit for the UTAs, i.e. learning through teaching [5].

\section{Program Description}

The UTA program at the University of Arizona mathematics department goes beyond using undergraduates solely as graders and tutors. Instead, it exposes UTAs to all aspects of teaching a college-level class.

To apply to the UTA program, students must score at least $80 \%$ on a college algebra and trigonometry test, submit a proposal outlining their planned UTA activities for a particular course, and obtain support from an instructor teaching that course. Based on applications, academic strengths, and seniority, approximately 13 students are chosen as 
UTAs each semester. Their class assignments range from Mathematics in Modern Society to Linear Algebra, with most UTAs assisting in first or second semester Calculus. At the University of Arizona, the majority of mathematics classes have an enrollment of at most 35 students, thus allowing the UTA (and instructor) to know all the students by name.

Before the start of the semester, the UTAs attend eight hours of training and orientation sessions. The training covers general information such as department policies as well as specific topics like grading, tutoring, and holding study sessions. A junior faculty member leads the training and coordinates the UTA program for one semester. In addition to training, the coordinator's duties range from recruiting, assigning, and mentoring the UTAs to evaluating and disseminating information about the program.

Throughout the semester each UTA works for ten hours a week, three of which are spent in the drop-in tutoring lab. In addition, each UTA assists with the teaching duties of her or his particular mathematics class for six hours. The responsibilities vary with each class and with the individual instructors. Typically, the UTA grades homework for the class and holds study sessions and office hours. Other activities include the development of classroom material, in-class assistance with group work, design and maintenance of a class webpage, holding review sessions before tests, and even substituting when the instructor is not available. 
The remaining hour each week is spent in training meetings with the other UTAs and the coordinator. The weekly meeting serves several purposes. First, it is a way for the coordinator to remain in contact with the UTAs. Second, it is a forum for introducing them to ideas in mathematics education. Some meetings involve guest speakers, such as the calculus course coordinator, and some are presentations by groups of UTAs. In the past, discussions have included topics such as different learning styles, different teaching styles, pros and cons of using graphing calculators, helping students deal with math anxiety, and how to obtain a secondary teaching certification.

At the end of the semester each UTA writes a final report about their experience as a teaching assistant. The reports are published at the UTA webpage: www.math.arizona.edu/ uta. In addition to writing this report, the UTAs are asked to complete a survey evaluating the UTA program.

\section{Program Evaluation}

Since its inception, the UTA program has been quite successful, impacting the mathematics department at many different levels. Below, we describe the benefits of the program to the UTAs, the department, and the students in the classroom.

\section{Impact on UTAs}

From their final reports and surveys, we found that the program was beneficial to UTAs in two main areas: improving their understanding of mathematical concepts and discovering an appreciation for (and a joy of) teaching. Several UTAs mentioned that they now have a much better understanding of the material after explaining it to their 
students. For example, one UTA writes: "By no means did I ever think that teaching or tutoring others could affect my knowledge on math to the extent that it did. In being pushed to explain some simple concepts I noticed myself thinking about these ideas and understanding them on a higher level." Another writes: "Teaching someone is truly the best way to understand what you are explaining."

From many comments on the final reports it became clear that the UTAs learned considerably about teaching mathematics during the semester. Some gained personal insights for their future career plans, leading some to apply for other teaching-related opportunities both on and off campus. As one student wrote: "Ever since entering academia, I had always given serious thought to some day becoming a teacher. I think this UTA program has made me more than ever committed to the idea that I will teach." Another wrote: "Being a science major I always felt I was limited to the options of research or medical school. By participation in this program over the spring 2001 semester I was able to discover a passion for teaching by assisting in the learning experience.... I now plan on continuing with majoring in biochemistry, but also am going to pursue a science teaching degree that can be earned upon graduation."

Other benefits often experienced include developing a relationship with a faculty member. Working closely with an instructor for a full semester gives the UTA an opportunity to demonstrate her or his interest in teaching, her or his willingness to take on responsibilities, her or his reliability as an assistant, and her or his ability to communicate mathematically with other students. This enables the instructor to write a meaningful, 
personalized letter of recommendation, especially if the UTA is applying to graduate programs or professional school.

Finally, creating a sense of community at a large public university can often be difficult. By meeting and working with students who possess similar interests and abilities, the UTAs develop their own meaningful community. Often, UTAs develop friendships and study groups that extend well beyond the completion of their assistantship.

\section{Impact on instructors and mathematics department}

In the past, instructors have been asked to complete a survey evaluating their experience with a UTA. From these surveys, we have seen that instructors who work with a UTA continue to request UTAs each semester. They especially value having a competent and reliable grader who not only grades, but also provides feedback on how the students are doing. Having a UTA allows the instructor to give students more individual attention during group work and study sessions. Moreover, instructors appreciate the fact that their assistant knows the students personally, not just as a name on a homework assignment. Their UTAs were able to develop meaningful relationships with students that had a significant impact on the learning process.

The mathematics department also benefits from the UTA program. Many mathematics departments provide support opportunities for students who are interested in mathematical research. The UTA program provides a way for the department to support students who are interested in teaching mathematics. Indeed, since the program's 
inception, six students who began the UTA program with majors other than mathematics have added a major or minor in mathematics or mathematics education during their experience as a UTA. In the long run, as more students benefit from the program, they appreciate the department's interest in improving the quality of undergraduate instruction.

There are also practical benefits for the department. Because the UTAs work in the lower-division tutoring room as part of their job, the number of people working in the tutoring room increases, thus improving the overall efficiency of the program. Instead of having to hire and train students who might not be taking mathematics, the department obtains tutors who are willing, interested, well trained, and already incorporated into the mathematics program.

\section{Impact on students}

\section{Pilot Study}

To evaluate the program's influence on the quality of mathematics instruction we investigated students' study habits and attitudes in their mathematics classes. We conducted surveys in classes with UTAs and similar classes without UTAs in two consecutive semesters. The surveys where given at the same time as the regular course evaluations. The first semester served as a pilot study and showed some significant results, such as:

1) Students with UTAs have more contact with their actual instructors than students without UTAs. 
2) Students with UTAs spend more time in their instructor's office.

3) Students with UTAs rated their out of class support higher.

\begin{tabular}{|l|c|c|c|c|}
\hline \multirow{2}{*}{ Statistic Measured } & Mean, students & Mean, students & Two-Sample & Two-sided \\
& with UTAs & without UTAs & T-Test & P-value \\
(\#) cosponses) & (\# of responses) & Statistic & \\
(times/month) & $2.71(218)$ & $1.54(216)$ & 4.14 & $<0.001$ \\
\hline 2) time in office hours & $1.58(217)$ & $0.96(216)$ & 2.72 & 0.007 \\
(hrs/week) & & & 3.69 & $<0.001$ \\
\hline 3) support rating & $4.07(204)$ & $3.68(197)$ & & \\
\hline (5=very much) & & & & \\
\hline
\end{tabular}

Table 1: Summary of results from pilot study

Other less significant trends warranted further study. For example, students with UTAs spent more time on average working in groups $(M=1.49$ vs. $M=0.79$ hours per week, $\mathrm{p}=0.193$ ) outside of class than students without UTAs.

\section{Follow-up Study}

Based on the previous results, we designed a follow-up study to investigate the trends further. Our hypotheses for the follow-up study were:

1) Students with UTAs spend more time on their class (than students in classes that do not have UTAs).

2) Students with UTAs spend more time working in groups.

3) Students with UTAs have more contact with their instructor. 
4) Students with UTAs rank out of class support higher.

5) Students with UTAs enjoy their class more.

6) Female students benefit more from a UTA than male students do.

The results of this study are summarized in the tables below.

\begin{tabular}{|c|c|c|c|c|}
\hline Statistic Measured & $\begin{array}{l}\text { Mean, students } \\
\text { with UTAs } \\
\text { (\# of responses) }\end{array}$ & $\begin{array}{l}\text { Mean, students } \\
\text { without UTAs } \\
\text { (\# of responses) }\end{array}$ & $\begin{array}{c}\text { Two-Sample } \\
\text { T-Test } \\
\text { Statistic }\end{array}$ & $\begin{array}{c}\text { Two-sided } \\
\text { P-value }\end{array}$ \\
\hline $\begin{array}{l}\text { 1) hours per week } \\
\text { spent outside of class }\end{array}$ & $7.05(121)$ & $5.81(109)$ & 2.23 & $0.026^{*}$ \\
\hline $\begin{array}{l}\text { 2) hours per week } \\
\text { spent in group work }\end{array}$ & 1.2 & 0.9 & 1.36 & 0.176 \\
\hline $\begin{array}{l}\text { 3) contact with inst. } \\
\text { (times/month) }\end{array}$ & 4.67 & 3.07 & 2.0 & $0.047 *$ \\
\hline $\begin{array}{l}\text { 4) support rating } \\
\text { (5=very good) }\end{array}$ & 4.017 & 3.684 & 2.6 & $0.01 *$ \\
\hline $\begin{array}{l}\text { 5) enjoyment rating } \\
\text { (5=very much) }\end{array}$ & 3.77 & 3.47 & 1.98 & $0.049^{*}$ \\
\hline
\end{tabular}

\begin{tabular}{|l|c|c|c|c|}
\hline \multirow{2}{*}{ Statistic Measured } & Mean, female & Mean, male & Two-Sample & Two-sided \\
& students & students & T-Test & P-value \\
& (\# of responses) & (\# of responses) & Statistic & \\
\hline 6) benefited from & $3.15(34)$ & $2.96(75)$ & 0.62 & 0.54 \\
\hline
\end{tabular}


UTA (5=very much)

Table 2: Summary of results from follow-up study

These results indicate statistically significant ( $\alpha \leq 0.05$ ) support for four of our original hypotheses. In particular, (1) students with UTAs seem to spend more time on mathematics outside of class, (2) have more contact with their instructor, (3) feel more supported, and (4) enjoy their mathematics classes more than students in classes without UTAs. We did not find significant evidence that students with UTAs spend more time working in groups nor did we find evidence that female students feel that they benefited from a UTA more than male students did. However, we noticed that women in classes with UTAs did spend more time on their class than did women in classes without UTAs. This difference was more significant than the corresponding statistic among men. It seems that having a UTA makes a bigger difference in class involvement for women than for men. Further studies into this question would be very interesting, especially since many institutions are looking for ways to attract more women as mathematics and science majors. Perhaps a future investigation would provide more significant support for these assertions.

\begin{tabular}{|l|c|c|c|c|}
\hline \multirow{2}{*}{ Statistic Measured } & Mean, students & Mean, students & Two-Sample & Two-sided \\
& with UTAs & without UTAs & T-Test & P-value \\
(\#) responses) & (\# of responses) & Statistic & \\
time spent on class & $8.51(35)$ & $6.15(31)$ & 2.08 & 0.042 \\
\hline Male students' time & $6.51(81)$ & $5.69(70)$ & 1.32 & 0.19 \\
\hline spent on class & & & & \\
\hline
\end{tabular}


Table 3: Time spent on class by female and male students

\section{Conclusions}

The Undergraduate Teaching Assistantship Program has been very beneficial to the UTAs, the instructors, and the mathematics students at the University of Arizona.

The program gives students interested in mathematics instruction a chance to gain multifaceted experiences in the field. The interaction with students gives them the opportunity to deepen their understanding of the material and especially to improve the skill of communicating this knowledge to others. Many UTAs continue to work as teaching assistants, either for the mathematics department again or for other departments, such as Computer Science. Some participate in the research aspect of the VIGRE program, and at least one has gone on to teach classes for the community through the Extended University Program. Moreover, some have added a secondary teaching certification to their existing major.

The instructors appreciate the assistance of motivated and well-qualified undergraduates in the teaching of their classes. The program allows them to offer additional services such as review sessions, extra office hours, review material, and out of class projects that would be hard, if not impossible without the assistance of a UTA. The department itself gains competent graders and well-trained tutors.

The students in the lower division mathematics classes with a UTA benefited from the additional out of class support for their course. They spent more time working on their 
coursework, felt more supported, and they enjoyed the class more. The students not only received additional help, but they also had the opportunity to seek help from somebody closer to their peer group.

We believe that including the UTAs in so many different aspects of mathematical instruction has contributed substantially to the success of the program. To ensure that this comprehensive approach remains vital, the program has evolved to provide instructors with ideas of how to enrich their classrooms by expanding UTA participation.

The ongoing nature of the UTA program at the University of Arizona (and others like it) provides a fertile environment to examine the long-term benefits of involving undergraduates in the undergraduate classroom. As we have seen here, such programs not only benefit the participants, they also serve the needs of the department and the students as well. 


\section{References}

[1] Baisinger, Wilbur H. et al. 1984. Undergraduates as Colleagues: Using Undergraduates as Teaching Assistants in the Basic Course. Association for Communication Administration Bulletin. 47: 60-63.

[2] Harper, Kathleen A. and David May and Keith Oliver. 2002. Using Undergraduate Students as Physics Lab Teaching Assistants. Physics Teacher. 40(4): 226-228.

[3] Kanaga, Kim R. 1979. The Evaluation of a Training Program for Undergraduate Teaching Assistants, Paper presented at the International Communication Association Conference.

[4] Larson, Charles U. 1990. Innovative Approaches to Teaching the Large Persuasion Class. Paper presented at the Annual Meeting of the Speech Communication Association.

[5] McGivney-Burelle, Jean and Thomas DeFranco and Charles Vinsonhaler and Kimberly Santucci. 2001. Building Bridges: Improving the Teaching Practices of TAs in the Mathematics Department. Journal of Graduate Teaching Assistant Development. 8(2):55-63.

[6] Osborne, Randall E and Joseph Norman and Tim Basford. 1997. Utilizing Undergraduate Teaching Assistants: An Untapped Resource. Paper presented at the Annual Conference on Undergraduate Teaching of Psychology. 


\section{Biographical Sketches}

Christopher Goff started in Fall 2002 as an Assistant Professor at University of the Pacific in Stockton, CA, after completing a three-year teaching postdoctoral position at the University of Arizona. He received his Ph.D. in representation theory from UC Santa Cruz in 1999. His current interests range from representations of twisted quantum doubles of finite groups to mathematical physics to the interaction of mathematics and gender.

Brigitte Lahme is an Assistant Professor at Sonoma State University in Rohnert Park, CA. After receiving her Ph.D. in 1999 from Colorado State University, she spent three years as a teaching postdoctoral fellow at The University of Arizona. Her interests include applications of representation theory in dynamical systems, models of peer instruction in the undergraduate program, and outreach with in-service teachers. 